\title{
Retour sur « La transmission des savoir-faire »
}

\section{Marie-Noëlle Chamoux}

\section{OpenEdition}

\section{Journals}

Édition électronique

URL : https://journals.openedition.org/tc/5100

DOI : $10.4000 /$ tc. 5100

ISSN : 1952-420X

\section{Éditeur}

Éditions de l'EHESS

\section{Édition imprimée}

Date de publication : 30 juin 2010

Pagination : 136-138

ISSN : 0248-6016

\section{Référence électronique}

Marie-Noëlle Chamoux, « Retour sur « La transmission des savoir-faire » », Techniques \& Culture [En ligne], 54-55 | 2010, mis en ligne le 30 janvier 2013, consulté le 29 septembre 2022. URL : http:// journals.openedition.org/tc/5100 ; DOI : https://doi.org/10.4000/tc.5100 


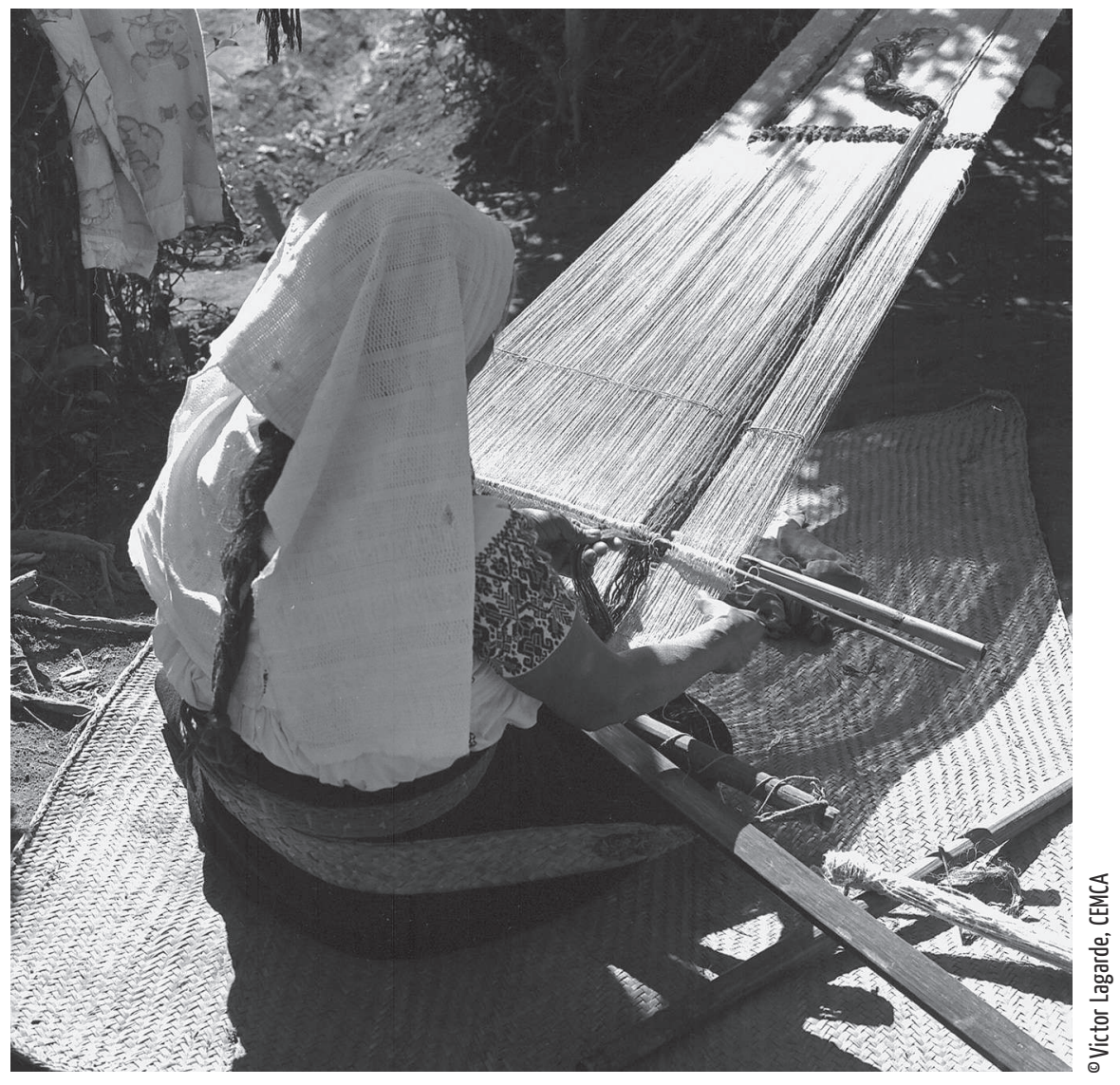




\section{Retour sur}

\section{« La transmission des savoir-faire »}

En 1978, ma démarche partait du constat que l'anthropologie des techniques semblait essoufflée, alors même que notre société parlait de plus en plus de technologie (industrielle ou moderne, certes). Il y avait là un hiatus, qui tenait peut-être à une manière trop étroite, de part et d'autre, d'envisager les rapports entre techniques et société. Cet article abordait les problèmes d'analyse et d'enquête que pose la transmission des savoir-faire techniques. Ceci peut sembler un thème courant aujourd'hui, mais ce n'était pas le cas alors. C'était même si inhabituel que je dus ajouter un prudent point d'interrogation au titre de l'article, et maintes fois il fallut expliquer que ce thème entrait bien dans les contours disciplinaires de l'anthropologie-ethnologie.

On saisira mieux la nouveauté en évoquant le contexte. À l'époque, en France, les outils conceptuels répandus dans l'anthropologie des techniques provenaient pour part de l'œuvre d'André Leroi-Gourhan ( " chaînes opératoires », « milieu technique »), pour part du marxisme («forces productives », « modes de production ») et pour part de l'ethnoscience (travaux de H. C. Conklin, « taxonomies indigènes »).

De plus, il était donné comme allant de soi que les techniques relevaient avant tout du domaine du «matériel ». Aussi la théorie des instances (marxisme structuraliste), posant une hiérarchisation allant du matériel, recteur, à l'idéologie, reflet, constituait-elle le paradigme scientifique. En conséquence, la méthode d'analyse généralement préconisée comportait deux temps: d'abord décrire les « chaînes opératoires » (niveau du rapport à la matière); une fois ceci fait, on pourrait s'interroger sur les phénomènes sociaux et culturels (niveau de la culture et des rapports sociaux), pour étudier, au choix, l'isomorphie des deux niveaux ou leurs liens de détermination mutuels.

Or j'avais des doutes sur la faisabilité ce programme. Que décrire et jusqu'à quel degré de détail? Comment déconnecter, pour les besoins de l'analyse, le «matériel » et le 
« socioculturel »? Ne trouvant pas de réponses convaincantes à ces questions, je cherchai comment découper l'objet d'étude selon d'autres principes, tenant dès le départ ensemble la technique et la culture ${ }^{1}$. Dans cette quête, sortir de la discipline officielle ethnologique ou anthropologique était une piste à suivre.

C'est par la migration d'un concept - le savoir-faire - qu'une solution fut entrevue. Le mouvement historique de modernisation, à cette époque, constituait l'arrière-plan indissociable des idées académiques. En sociologie rurale, des interrogations sur le « savoir paysan » se développaient, en réaction au bouleversement constitué par la technicisation de l'agriculture et « la fin des paysans ». Mais c'est dans la sociologie du travail industriel et dans l'ergonomie que se trouvait un concept capable de découper un objet consubstantiel à l'action sur la matière et aux rapports socioculturels. Le débat sociologique, en résonance avec le mouvement social et la mise en doute du taylorisme, portait alors sur les « qualifications », à partir de la notion de savoir-faire ${ }^{2}$. Je la fis donc migrer pour traiter mes matériaux sur les Indiens du Mexique.

Il était tentant de s'engager sur la piste qui consistait à remplir la nouvelle case « savoir-faire » identifiée en s'engageant dans une approche folkloriste, ou dans l'amélioration des descriptions ethnographiques en empruntant les méthodes de l'industrie. Cependant, ce ne fut pas le chemin choisi, car il éloignait de l'étude des articulations entre le «matériel » et le «social».

Un sujet d'études parut plus fécond. Dans l'expérience ordinaire, on observe des situations paradoxales: la réussite de la transmission des savoir-faire est courante et elle s'accommode de l'informulation relative du contenu du savoir. Ma démarche consista donc à déplacer l'angle d'attaque des phénomènes pour le faire porter sur la transmission des savoirfaire techniques et sur les modalités multiples de leur appropriation. Constater les succès et les échecs, retracer les limites et les chemins de la circulation des savoir-faire techniques fut donc l'heuristique choisie. Ce fil conducteur, appliqué à mes documents de terrain, fit reconsidérer des catégorisations routinières en anthropologie (par exemple la « division sexuelle du travail », qui n'est pas une division des savoir-faire), donna un regain d'intérêt pour le thème de l'éducation, posa la question du contrôle social des savoir-faire dans sa variabilité historique, loin des apparences de spécialisations figées de groupes sociaux.

Le thème de la transmission des savoir-faire techniques a été repris dans l'ethnographie de la France (dans les appels d'offre du Ministère de la culture à partir de 1980). L'équipe Technique et culture fit évoluer son projet pour y inclure ce thème ${ }^{3}$. Des retombées se sont manifestées aussi en préhistoire. Une version légèrement différente et sans schémas ni illustrations fut publiée en 1981 dans la revue L'Homme ${ }^{4}$ (Chamoux, 1981).

Larticle présente des suggestions de concepts utiles pour le décryptage, par un observateur externe, de la construction et de la circulation des savoir-faire: combinatoire de la compétence et de la performance techniques; distinction entre savoir incorporé vs algorithmisé de Barel (1977), comparable à celle de savoir procédural vs propositionnel, vue plus tard chez Jorion ${ }^{5}$ (Delbos \& Jorion 1984); répartition des savoir-faire entre les groupes sociaux et son évolution; méthodes pédagogiques multimodales, etc. Il donne les éléments d'un programme de recherche dont certains axes seront approfondis par la suite, sans jamais oublier le caractère éminemment historique, et donc relatif et évolutif, des phénomènes observés. 